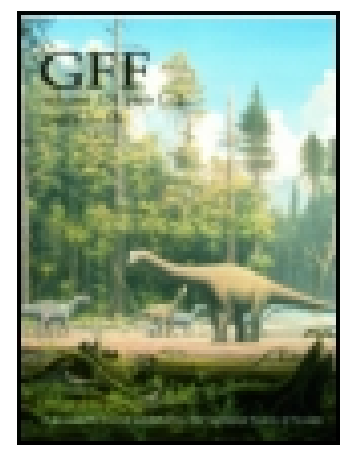

Geologiska Föreningen i Stockholm Förhandlingar

\title{
Apofyllit från några svenska fyndorter
}

\section{Gust Flink}

To cite this article: Gust Flink (1906) Apofyllit från några svenska fyndorter, Geologiska Föreningen i Stockholm Förhandlingar, 28:6, 423-450, DOI: 10.1080/11035890609445530

To link to this article: http://dx.doi.org/10.1080/11035890609445530

$$
\text { 曲 Published online: } 06 \text { Jan } 2010 .
$$

Submit your article to this journal ¿

Џll Article views: 4

Q View related articles ¿ 
Apofyllit franı nigra srenska fyudorter.

\author{
Af \\ Gust. Flink.
}

A pofyllit kan sägas vara ett ursprungligen srenskt mineral. Det uppmärksammades nämligen fürsta gângen vid Hällestad i Ostergötland af Carl Rrsmax, som sedan i Vet. Akad. Handl., Bd 5, 1784, s. 52, under rubrik sFörsök med \%eolith eller Güssten» redogjorde för sina undersökningar â detsamma. Redan förut voro zeoliter künda från åtskilliga fürekomster, och Risuax visade nu, att Hällestad-mineralet hörde till dessa, men också att det på grund af sin sammansättning borde räknas som en egen art af dem. Nảgot särskildt namn föreslog han dock icke für sitt nya mineral. Sedan antrüffades detta flerstädes både $i$ ntlandet och i Sverige. Ett eget namn erhöll mineralet först af AxDRADA, som kallade det af honom i Utö grufvor funna Ichtyoftalm. ${ }^{1}$ Detta namn ansâgs dock af $\mathrm{HAÜr}_{\mathrm{i}} \mathrm{i}$ viss mån vara tretydigt, och han utbytte det mot det sedan allmänt använda apofyllit. ${ }^{2}$ Sjülf hade han förut kallat mineralet (frản Island) Mésotype épointée. ${ }^{3}$

Några mer ingående undersökningar eller beskrifningar pả svenska apofylliter hafva sedan Rrwuss till icke blifvit gjorda. De knapphändiga uppgifter $\mathbf{i}$ detta ämne, hrilka antrufffas i litteraturen, üro helt $\mathrm{i}$ förbigneende framliastade af

I Scheerer's Journ. 4, 1800, s. 32.

= H.ter: Notes pour servir an Cours de Minéralogic, de l'an XIII (1805).

" Traité de Min., III, 1801, p. 1̄̄y. 
med förhãllandena föga förtrogna utlänningar. Att $i$ nâgon mản utfylla den lucka, som sâlunda förefinnes i kännedomen om de srenska apofyllitförekomsterna, ̈̈r afsikten med föl. jande framstïlluing.

\section{Apofyllit från Nordmarken.}

I Nordmarks grufvor, belägna 15 lim nordligt från Filip. stad, har apofyllit varit künd sedan lång tid tillbaka och emellanât föreliommit rätt ymnigt. Redan i andra upplagan af Hisingers Mrineralgeografi öfver Sverige, som utkom âr 1826, meddelas det, att i Grundsjögrufvan förekommer apofyllit dels som tunna, små, rätvinkliga taflor med alla hïrn

Fig. 1.

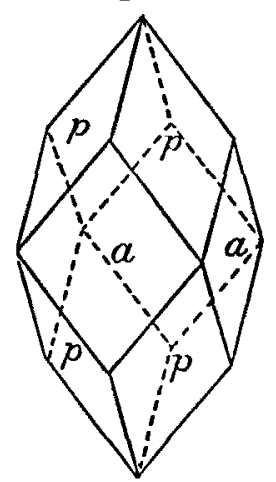

och lianter mer eller mindre afstympade och dels $i$ den ranliga pyramidala formen. IaELströ̀ angifver, ${ }^{1}$ att han pâ 1870-talet sett centnertunga block af mineralet, nyss uppfordrade ur grufvan. Dessa bestodo dels af vanliga pyramidala kristaller och dels af loncentrisht strâliga (skall väl vara bladiga) kulor med 2-3 $\mathrm{cm}$ genomskärning.

Hittills är apofylliten fiån Nordınarken künd under $\ddot{3}$ olika kristalltyper.

Till första typen rüknas de ranliga pyramidala kristallerna (fig. 1). I de flesta fallen äro dessa kristaller rätt smá,

I G. F. F. 7 (18S5): 4 . 
oftast mindre än $1 \mathrm{~cm}$ i tvärmátt, och bilda krustor och sanmanhängande druser pả andra mineral, i synnerhet hornblende. Stundom kunna dessa kristaller dock nả en längd af $3 \mathrm{~cm}$. Några andra former än $\mathrm{p}\{111\}$ och a $\{100\}$ förekomma icke. Itorna äro alltid mer eller mindre ojümna och gifva â goniometern ett virrrarr af reflexer. Pyramidytorna äro uppdelade i oregelbundna, sinsemellan icke parallella failt, risa streckning i olika riktningar, buktighet 0 . s. v. Prismaytorna ïro ock streckade, men regelbundet $i$ vertikal riktning.

Till fürgen äro dessa apofyllitkristaller sinsemellan nâgot olika. I rent tillstând äro de naturligtvis färglösa och genomskinliga. Men ganska ofta hysa de inneslutningar af främmande substans, som gör dem pâ ett eller annat sätt fürgade. Ofta innehålla de ett lerartadt slam, hvilket sannolikt är identisht med det, som förekommer i de flesta drusrum i dessa grufror. Kristaller med denna inneslutning äro askgrå och ogenomsiktiga. Stundom äro kristallerna rökffirgade till nästan svarta. Det pigment, som förorsakar denna fürgning, är sâ finfürdeladt, att det icke ens vid starkaste förstoring kan ialittagas. Tunna plattor af sålunda fürgade kristaller äro trärtom helt färglösa. På senaste tiden har man funnit kristaller med inneslutningar af små kloritfjäll, hvilka ligga anordnade i zoner strax innanför kristallytorna, men alltil helt inneslutna. Dessa kristaller äro i öfrigt fullt klara och visa en svag dragning åt rödt.

Till andra typen räknas tjockt tafrelformiga kristaller, d. v. s. sảdana, hos hvilka tjockleken är ungefür hälften så stor som bredden (fig. 2). I största utstrüclining hålla de vanligen $1-303 \mathrm{~cm}$ och sitta anräxta sả, att tafvelplanet bildar omkring rüt vinkel med underlaget. De vända alltsâ medelkanter och prismaytor utảt och äro i sådan stïllning tätt grupperade till ansenliga druser. 'Till ytkombinationen äro afven dessa kristaller af enklaste beskaffenhet, då blott följande former uppträda:

$$
\text { c }\{001\}, p\{111\} \text { och a }\{100\} \text {. }
$$


Basisytorna äro hür alltid starkt drusiga, luvilket beror pả, att de aro uppdelade $i$ ett stort antal rätrinkliga smáytor, som icke ligga fullt i samma uivå, men intaga i öfigt sinsemellan parallell orientering. Man kan säga, att hrarje hufrudindivid i sina yttersta lager mot hasis upplüser sig i ett stort antal smaindivider, hrilka hvar och en begränsas af sina basis- och pyramidytor. De basiska småytoina äro ranligen matta, men de för mineralet utmärkande interferensfürgerna skina dock igenom. Kristallernas öfriga ytor üro visserligen starkt glänsande, men däremot my'cket ojämna. Särskildt gäller detta pyramidytorna. De äro buktiga, brutna och streckade pâ mångfaldigt sütt, men någon regelbundenlet i dessa företeelser lảter icke pảvisa sig. Prismaytorna üro afven streckade, men icke som vanligt i vertikal riktning, ntan

Fig. 2.

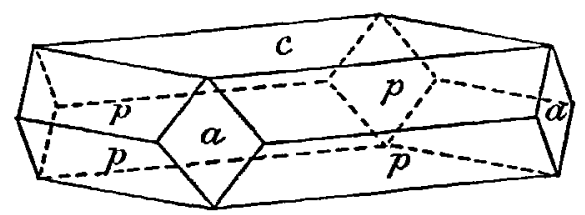

fjülerformigt, parallellt med kombinationskanterna till pyramidytorna.

De hithörande kristallerna äro färglösa och vanligen vattenklara. Stundom äro de i vissa partier genomsatta af en müngd ytterst fina sprickior, mot hvillia ljuset ảterkastas, och mineralet erhåller härigenom ett mjölkhritt utseende. Stundom innehålla äfven dessa kristaller det vid föregående typ omnämnda, leraktiga slammet, och de ïro dả askgrå till färgen. Pả kristallytorna sitta stundom ytterst smả svafvelkiskristaller anväxta. Den nu beskrifna typen af apofyllit från Nordmarken synes hafva förekommit blott på senare tiden och i ringa mängd.

De till tredje typen hörande liristallerna äro trifrelsutan identiska med de af Hisixger nämnda, tunna taflorna med afstympade hörn och kanter, ehuru det material, hvarpã föl- 
GEOL. Fören. FörilaNDL. N:o 244 . 13d 28 . IIäft. 6 .

jancle beskrifning grundar sig, anträffats först i senare tid. Denna ntbildningsform är för lokalen helt risst ganska sällsy'nt, ty i Riksmuseets samlingar finnas blott nàgra fả stycken düraf.

Nineralet har utbildat sig i sprickor i jürnmalmen. Vüggarna i dessa sprickor blefvo först bekliddda med ett lager af amfibol-hornblendeskarn, därefter afsatte sig en krusta af kalkspat, hvarpå rummet till största delen utfylides af apofyllit. Pả grund häraf hafra de största och flesta apofyllitindividerna icke haft plats att utbilda sig till idiomorfa kristaller. Men här och hrar $\mathbf{i}$ de bladiga massorna förekomma smiirre mellanrum, och $\mathbf{i}$ dessa anträffas visserligen små, men utomordentligt väl utbildade kristaller. De ïro vanligen ganska tunt tafvelformiga efter basis och ofta jämförelsevis ytrika.

Vid rinkelmätningar, som företogos för att bestämma nảgra observerade, mindre vanliga former, bekrüftades, hvad som redan det ytliga betraktandet lät förmoda, nämligen att här alldeles exceptionellt fullkomliga kristaller förelảgo. De särskilda ytorna gifva nümligen fullt skarpa och enkla reflexbilder, motsatta ytor üro ofta absolut parallella, och vinkeln melkan t. ex. (100) och (001) afviker sällan märkbart frân det teoretiska vïrdet $90^{\circ}-$. Men düremot visar det fullt noggrant bestämbara värdet pả vinkeln (111):(001) en icke oväsentlig afvikelse från det för mineralet antagna rärdet 10'32'. Ur detta värde är mineralets allmänt antagna axelförhảllande beräknadt af $\mathrm{W}$. H. MILLER, ${ }^{2}$ nämligen

$$
\mathrm{a}: \mathrm{c}=1: 1.2515
$$

Nämnda fundamentalvinkel är däremot pả de vial ntbildade Nordmarkskristallerna funnen $=600^{2} 6^{\prime}$, hrarur axelförhållandet

$$
a: c=1: 1.2464
$$

1 Phillips' Jincralogy, 150?, p. 436. 
framgår. Afvikelsen ir ju icke stor, men mätningarna üro sâ noggranna och öf verensstämmande, att de omöjligen kunna förenas med de äldre värdena.

Emellertid hafva olika forskare fumnit värdet pả demna rinkel ganska olika. DaubeR ${ }^{1}$ fann pả material frân Seiseralp 60:3t', LUDECKE ${ }^{2}$ pả dylikt från Andreasberg 59'37', och flera andra hafva fastställt talrika mellanliggande värden. Denna brist på öferensstämmelse ür dock lätt förklarlig. De allra flesta apofyllitkristaller gifva nämligen på goniometern en hel serie af reflexer, och det är i de flesta fall omöjligt

Fig. :3.

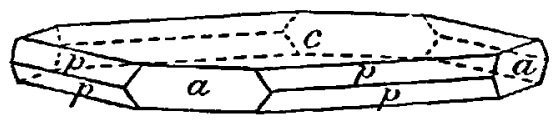

att afgüra, hvilken af dem företrädet bör tillerkïnnas. För vinnandet af ett tillförlitligt resultat ür därför ett omsorgsfullt val af material oundgüngligt, och ett tadelfritt sâdant

Fig. 4.

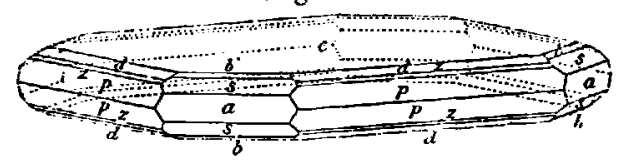

torde blott süllan stå till förfogande.

De former, som blifrit ialittagna och bestitmda pã nu i fråga rarande liristaller äro följande:

c $\{001\}, a\{100\}, p\{112\}, z\{113\}, d\{115\}, s\{102\}, b\{103\}$ och a $\{311\}$.

Af dessa är det de tre förstnämnda formerna, som bestämma kristallernas habitus (fig. 3), och som alltid äro för handen. De andra äro däremot underordnade och utgöra vanligen smala afstympningar pâ vederbörande lanter. Fig. 4 risar en kom-

1 Bog\%. Ann. 107, 1S599, s. 281.

Z Zcitschr. f. d. Ges. Naturw. 51. 1578. s. 129. 
GEOL. FönEx. FöRHANDL. N:o 244. Bd 28. Haft. 6. 420 bination af samtliga formerna, utom $\alpha$, som är mindre vanlig ün de öfriga. Dess läge åshîdliggöres genom fig. 5 .

Såsom redan angifvits, utmärka sig dessa kristaller sïrskildt för sin fullkomliga ntbildning. Samtliga ytor äro vanligen utan alla ojämnheter och starkt glänsande. Äfven formen a, som eljest nästan alltid ür starkt streckad, är här lika jümn som nãgon af de öfriga formernas $y$ tor.

Alla de angifna formerna äro fürut kända hos apofyllit. DaxA ${ }^{1}$ betecknar formen $b$ sảsom osäker. Den anföres af $P$. I. Ploner ${ }^{2}$ jämte en stor mängd vicinalformer pâ apofyllit från Seiseralp i Tyrolen.

Fin. $\bar{x}$.

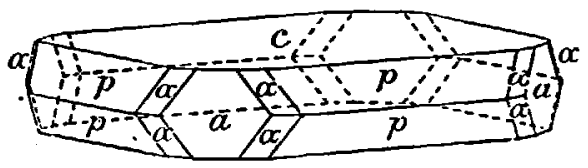

De särskilda formernas bestämning grundar sig pâ följande vinkelvärden:

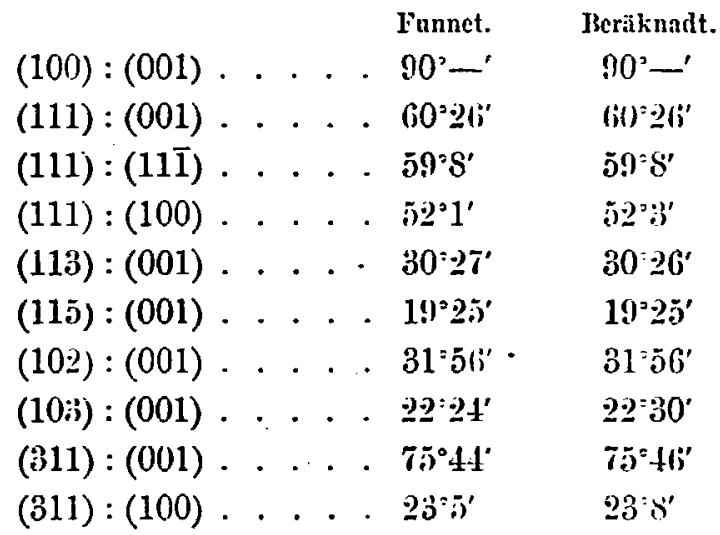

1 System of Ylineralogy, 1892, p. 567.

2 Zeitschr. f. Kryst. 15, 1590, s. 337. 
Äfren i de omedelbart invid Nordmarksgrufvorna belägna 'labergs grufvor har man pà senare tiden anträffit apofyllit i afsevärd mängd. Mineralet från denna lokal hur välkristalli. seradt och individerna stundom rätt stora ${ }^{1}$ De tillhöra den ranliga, spetsigt pyramidala typen (fig. 1), men spetsarna üro här $i$ de flesta fall afstympade af smã basisytor. $D_{e}$ företrädda formerna är alltså blott följande trenne:

$$
p\{111\}, a\{100\} \text { och } c\{001\} \text {. }
$$

Alla ytor pâ dessa kristaller äro starkt glänsande, men pâ de större individerna äro de vanligen ganska ojầmna.

\section{Fig. 6.}

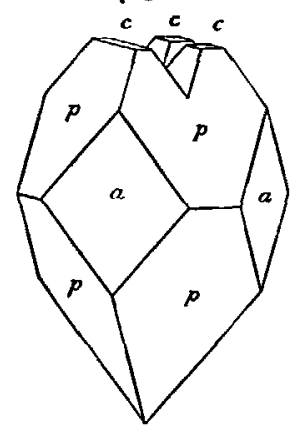

Basis är dock alltid jümn, och äfen de delar af pyramidytorna, som ligga närmast basis, äro ofta jämna. De större kristallerna upplösa sig ofta i flera spetsar (fig. (i). Spetsarna äro alltid vattenklara, hvaremot kristallemas centralare delar äro något grảaktiga och grumliga.

De smärre bristallerna, som hålla blott några fả millimeter $i$ tvărmått, visa sig äfren här vara förträffligt utbildade med såval pyramid- som basisytor så jümna man lan ïnska. Vì vinkelmätning på dessa kristaller kunna därför mycket noggranna värden erhållas. De vinklar, som pyramidytorna bilda sinsemellan, äro mycket konstanta, hraremot

I I Stockholms IHügskolas samling finnes en kristall, som är $6 \mathrm{~cm}$ hög och $3 \mathrm{~cm}$ i triirmatt; den ïr visserligen etiketterad: Nordmarken, nen stammar helt säkert från Taberg. 
GEOL. Förex. FörhaxdL. N:0 244. Bd 2S. IIIff. b. 431

basisytornas läge synes vara något oregrelbundet. Om sâlunda rinkeln $(111):(\overline{11} 1)=120^{\circ} 40^{\prime}$, sả $\operatorname{kan}$ på samma kristall $(111):(001)$ vara $60^{\circ} 30^{\prime}$ och $(\overline{11} 1):(001)=60^{\prime} 10^{\prime}$. Bätre material för bestämmande af apofyllitens axelförhâllande än det, som dessa smürre kristaller från Taberg erbjuder, kan dock säkerligen icke fảs. Emellertid har jag gjort kontrollbestämningar pâ kristaller af utmärktasto beskaffenhet från Theigarhorn vid Berufjord, Island, ${ }^{1}$ och resultatet har för båda förekomsterna blifrit fullstïndigt detsamma. Polkantsvinkeln $(111):(1 \overline{1} 1)=75^{\circ} 50^{\prime}$ och medeliantsvinkeln $(111):(11 \overline{1})=59^{\circ} 18^{\prime}$. Härur beräknas axelförhållandet

1 Dessa kristaller, hraraf lüsa exemplar finnas såväl i den Sjügrenska samlingen, Riksmuscum (N:o 3626), som i A. Ilasuengs privatsamling: aro utbildade s̊̊, som vidstảende figur visar. I trärmått hålla de c:a $1.5 \mathrm{~cm}$, och lïngden skulle vara ca $4 \mathrm{~cm}$, om hela exemplar fürelåge. Ilen vanligen är blott ena halfran utbildad, och det parti, med hvilket de varit anvixta pã underlaget, markeras af en basisk klyfyta. Itkombinationen bestâr af füljande former:

$$
\text { a }\{100\}, p\{111\}, c\{001\}, y\{310\}, r\{210\} \text { och } z\{113\} \text {. }
$$

Dessutom förekommer på kombinationskanten mellan a och p en srag antydan till afstympning, sannolikt af formen $\{311\}$, men någon tillfürlitlig bestämning lıar här icke varit möjliğ.

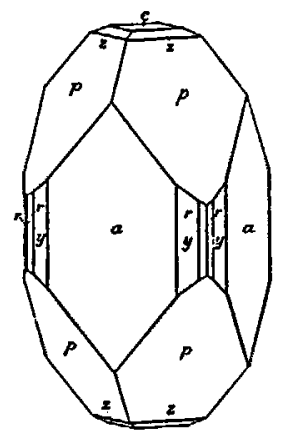

Jed .undantag af de till formen $z$ hörande ytorna, som äro nästan helt matta, äro santliga ytor högst glänsande och vanligen helt jämna. Basisytorna kunna i detta hänseende sägas vara ideala, äfven grundpyramidens ytor äro vanligen helt jämna, isynnerhet de delar af dem, som ligga närmast toppen. Ttorna af formen a visa däremot en vågighet eller veckning $i$ rertikal riktning, hvilken icke kan betecknas som ranlig kombinationsstreckning.

De delar af kristallerna, som gränsat närmast tili moderstenen, äro något grumliga, men i öfrigt är mineralet fullständigt vattenklart. 


$$
\mathrm{a}: \mathrm{c}=1: 1.2+215
$$

och rinkeln $(111):(001)=60^{\prime} 21^{\prime}$. Det pả Nordmarkskristal. lerna erhâllna värdet var $60^{\circ}-26^{\prime}$. Dả nu bảda bestämningarna äro fullt noggranna och hvar för sig överensstämmande, sâ måste en olikhet $i$ vinkelvärden hos de bâda kristalltyperna fürefinnas. Orsaken till densamma kan här icke angifvas. Möjligen beror den jå en olikhet i sammansättningen. A. Hexisisg ${ }^{1}$ har påvisat, att apofylliten, då den vid upphettning afger ratten, undergảr en betydlig vinkelföründring. En dylik omvandling visar sig naturligtvis äfven däri, att mineralet blir mer eller mindre opakt. Men något sådant har icke kunnat iakttagas hos nâgon del af det material, som behandlas i. denna uppsats. Det måste alltsammans betecknas som fullt friskt och af ursprunglig sammansättning.

\section{Apofyllit från Utö.}

De för snart en mansålder sedan öfrergifna jürnmalmsgrufvorna pả Utön voro synnerligen rika pả apofyllit, hvilket framgår bland annat däraf, att man än $i$ dag nästan öfverallt i le gamla skarnhögarna dïrstädes kan se vittrande massor af detta mineral. Dả portugisaren AxDRADA ${ }^{2}$ i slutet af 1700-talet under sin mineralogiska resa i Srerige och Norge besökte Utön, fann han, utom petalit, spodumen och incligolit,

1 G. F. F. ㄴ1 (1899): 397.

2 Denne mürklige man, hvars fullständiga namn var José BosIFAcio DE AsDrido E Sicva, füddes 1765 i Santos, Brasilien, af portugisiska föräldrar. IIan studerade bergstetenskap i Freiberg, blef professor i mineralogi i Coimbra, därefter i fysik i Lissabon och ändtligen generalintendent für det porlugisiska bergsväsendet. År 1819 återvände han till Brasilien, blef där statıminister och rid kejsar l'edro I:s abdikation af denne utnämnd till formyndare för hans son Pedro II. Ilan dog som privatman i Rio Janeiro 183S. I den srenska litteraturen synes icke finnas någon alygift om hans resa härstädes. Af hans egen korta beskrifning pia de i Skandinavien funna nya mineralen, hvilken utkom 1800, framgår blott, att den mảtte ägt run de sista åren af 1700-talet. Vidare kan af nttrycket - meinen letzten Reisen in Schweden und Sorwegen, - dragas den slutsatsen, att han varit här mer än en gång. 
GEOL. Förex. FürhaNdL. N:0 244 . Bd 28. HIäft. 6.433 iffen apofylliten, hvilken han, såsoin redau ïr nämndt, kallade ichtyoftalm. Den första noggrannare apofyllitanalys utfördes 1505 af Fourcroy och Vauquelis pả material från Utö. ${ }^{1}$ I HISIxGER's mineralgeografi af 1806 meddelas, att apofylliten förekommer i Utö grufvor under tre olika typer, men beslirifningen är sådan, att de svårligen kunna identifieras. $18+3$ års upplaga af samma rerk innehâller en betydligt modifierad beskrifning, men afven denna later knappt fnllt aupassa sig på nu künda typer af mineralet.

Äfven på nu tillgängligt material af apofyllit från denna fürekomst kan man dock sürskilja tre skarpt begränsade ntbildningsformer. Kristallerna äro nämligen antingen

1. Tafrelformiga,

2. Tärningformiga eller kort prismatiska eller ock

3. Pyramidala.

De tafvelformiga kristallerna kunna, i motsats till dem frãn Nordmarken, nả en betydlig storlek. I Stockholms Högskolas samling finnas tvả exemplar, af hvilka det ena hâller

Fig. 7.

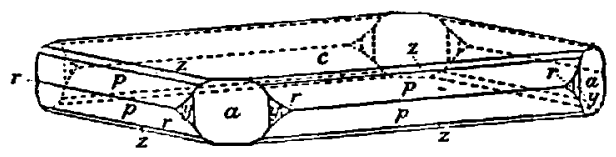

offer $6 \mathrm{~cm}$ i trürmâtt och $8 \mathrm{~mm}$ i tjocklek, det andra resp. $5 \mathrm{~cm}$ och $11 \mathrm{~mm}$. De aro tafrelformiga efter basis och begränsas af följande ytkombination (fig. 7):

$$
\text { c }\{001\} \text {, p }\{111) \text {, a }\{100\}, y\{310\}, r\{210\} \text { och } z\{113\} \text {. }
$$

Basisytorna äro nảgot matta, men förete dock vackra interferensfürger (perlemorglıns). Vid förstoring visar sig mattheten bero pả tütt ställda etsfigurer med rund eller oregelmässig begränsning. Dylika etsfigurer förekomma äfven på grundpyramidens ytor, men där üro de icke sả talrika, hvar-

1 Ann. Jus. d'Hist. Nat. 5, 1805, 317. 
för ock dessa ytor äro mer glänsande. De till formen z hïrande $y$ torna äro fint streckade efter sin lüngdriktning och ytorna i rertikalzonen likaledes parallell med axeln für nämnda zon.

Dessa kristaller äro på grund af sin storlek nãgot obekräma för vinkelmätning, men ytorna gifva rätt skarpa och enhetliga reflexer. Pả en af dem erhöllos följande värden:

$$
\begin{aligned}
& (111):(001)=60^{\circ} 20^{\prime} \\
& (111):(11 \overline{1})=59^{\circ} 13^{\prime} \\
& (113):(001)=30^{\circ} 24^{\prime} .
\end{aligned}
$$

De tafvelformiga kristallerna synas hafra varit de, som oftast förekommit i Utö grufvor, ehuru de sïllan torde hafva Fig. 8.

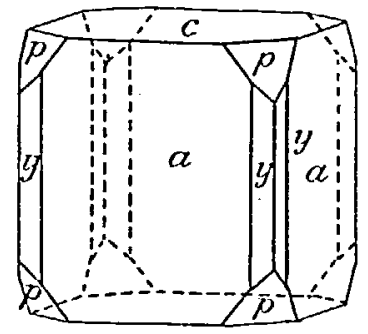

uppnått sảdan storleli som cle nu beskrifna. Äfven torde räl utbildade kristaller hafva jümförelsevis sällan förekommit. I skarnhögarna finner man mineralet vanligen i form af bladiga massor utan bestämbar kristallbegränsning.

De tärmingformiga eller liort prismatislia kristallerna torde äfven hafva förekommit ganska rikligt, då talrika stuffer med dylika kristaller förefinnas i samlingarna. De enskilda liristallindividerna af denna typ äro af medelstorlek, d. v. s. c:a $1 \mathrm{~cm}$ i genomskärning, men exemplar på $3 \mathrm{~cm}$ förekomma

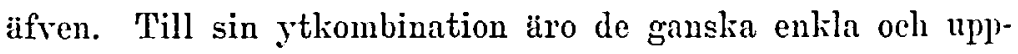
visa såsom hufvudformer blott (fig. S):

a $\{100\}$ och c $\{001\}$

samt mycket underordnadt formerna: 
GHOL. FörEs. FöRHANDL. N:0 ․4. Bd 28. lläit. 6.

p $\{111\}$ och y $\{310\}$.

Basisytorna äro hos dessa kristaller ännu mer matta än los de af föregiende typ. Vid förstoring risa de sig såsom ett mosaikverk af $\mathrm{i}$ något olika nivå belägna rektangulära småytor, som shiljas från hvarandra genom djupa inskïrningar, begränsade af till grundpyramiden hörande ytelement. Formen a är företrïdd af starkt streckade och mycket ojümna ytor. Den andra prismatiska formen, $y$, är sallan distinkt ntbildad utan utgör oftast blott en obestämbar tillrundning på kristallernas vertikalkanter. De pã hörnen uppträdande pyramidala afstympningarna äro glänsande, men sällan fullt jämna. Dessa kristaller äro således olämpliga för noggranna vinkelmätningar.

De pyramidala kristallerna torde fa anses som de intres. santaste apofyllitkristaller, hvilka öfver hufvud äro kända. De üro ock utomordentligt sällsynta, då så vidt kändt är, blott 6 stuffer däraf existera. Tre däraf finnas i Riksmuseets samling, en i Uppsala universitets samling, en äges af herr Seltamaxi i Coblentz, men hvar den sjätte f. $n$. befinner sig, är ovisst.

Hisinger uppgifver, ${ }^{1}$ att apofylliten förekommer på Utön shögst sallan i fullkomligt klara kristaller med stark glans, af den form, som öfverensstämmer med HAÜy's Mésotype épointée, men hvars alla lanter üro afskurnas. Den hürmed assyftade, af $\mathrm{H}_{A \ddot{U} Y}$ gifna beskrifningen gäller apofyllit från Island, och hans afbildning är lika med fig. 1, sid. 424. Tänker man sig alla kanter på denna figur afskurna, så erhålles en form, som ingalunda öfrerensstämmer med de kristaller, som här nu föreligga.

Dessa kristaller aro redan förut beskrifna $i$ en förträfflig uppsats af $G$. Seligmans, ${ }^{2}$ och föga är att tillägga utöfver hvad denna beskrifning innehåller.

1 Ilandbok för Jineraloger nnder resor i Sverige, 1843, sid. 99.

2 Nanes Jahrbach f. Jineralogie ctc. 5̃: 1, 1880, 140. 
Moderstenen, hvarpã mineralet förekommer, utgöres af en grågrön skarmmassa, som hufvudsakligen består af klorit och jairnmalm, mest järnglans. Närmast under liristallkrustorna är järnglansen ofta utsöndrad i små körtlar med ranlig romboedrisk afsöndring.

Apofyllitkristallerna hafra en svagt rosenröd färg och äro helt kla'a och genomsilitiga. De äro rätt smả, dâ sällan någon individ uppnảr en storlek af $1 \mathrm{~cm}$; de flesta torde vara c:a $5 \mathrm{~mm}$ i genomsnitt. De sitta taitt grupperade i druser och äro därfür fritt utbildade blott på en sida. I kristalldruserna förekomma stundom bladiga massor af mörkgrön klorit. Vidare visa sig här och där bland kristallerna små gyttringar af nästan mikroskopiska kulor af ett mörkbrunt mineral, som synes vara limonit eller något dürmed besläktadt. Dessa minimala gyttringar aro ofta regelmässigt anordnade pả midten af apofyllitkristallernas basisytor. De smá kulorna äro ofta ordnade i rader och bilda sålunda smả mörka stafvar, hvilka äro orienterade diagonalt på midten af de rektangulära basisytorna.

Dessa kristallers pyramidala habitus betingas hufrudsakligen af grundpyramiden, som väl i de flesta fall är den dominerande formen. Men hufvudformen modifieras så starkt af alla de andra formerna, att bristallerna synas tillrundade, nästan kulformiga. Helt risst üro dessa de ytrikaste apofyllitkristaller, som äro kända.

Seligarans bestämde på dem följande former: $c\{001\}, \quad a\{100\}, y\{310\}, r\{210\}, \mathfrak{m}\{110\}, p\{111\}, \quad z\{113\}$, $\mathrm{x}\{1.1 .10\}, \mathrm{s}\{102\}, \mathrm{v}\{105\}, \alpha\{311\}$ och $\mathrm{i}\{101\}$.

Sistnämnda form, i, fann Selramaxx pâ blott en kristall. Den har icke kumnat återfinnas på Riksmnseets material. Alla de andra formerna äro däremot lionstaterade och dessutom trâ för denna lokal nya, nämligen:

$$
d\{115\} \text { och } f\{421\} \text {. }
$$


Geol. FöreN. FörnhaNd. N:o 944. Hd 28. Ilâft. 6. 437

Hela kombinationen, med undantag af formerna d och $\mathrm{x}$, iterges af fig. 9, hvaremot de sistnämda formernas läge âskådliggüres genom fig. 10, som är en ortografisk projektion på basis.

Eig. 9.

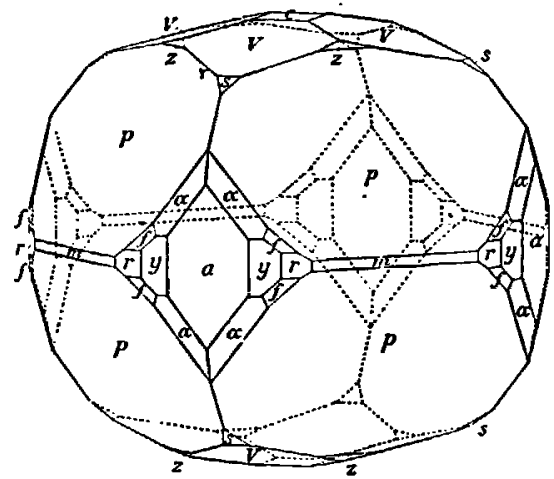

Fig. 10.

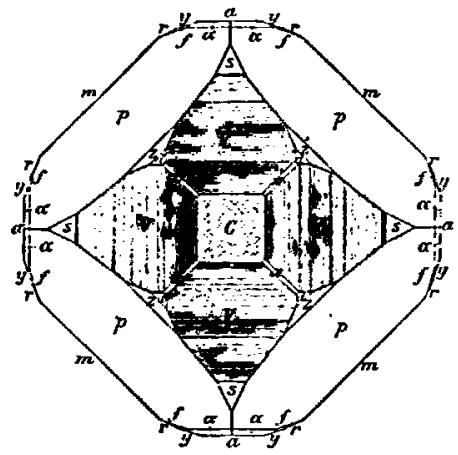

Basisytorna äro vanligen helt små, af kvadratisk form och begränsade af de till deuteropyramiden V hörande ytorna. De äro försedda med en ytterligt fin streckning, rutformigt $i$ diagonal rilitning, men $i$ ofrigt ntmärkt jämna och starkt glänsande.

Andra artens pyramid $V$ arr en af de dominerande formerna. Dess ytor äro fint och tiitt streckade parallellt med 
deras kombinationskanter mot basis. Därigenom uppstîr â dem ett slags vacker sidenglans, men de gifva sällan för vin. kelmätning brukbara reflexer. Den andra pyramiden af samma art, s, är företrädd af mycket smâ, triangulära ytor, hvilka också äro streckade i samma riktning som de af füregâenile form. De äro dock starkt glänsande.

Hufrudformen, grundpyramiden p, består af starkt glänsande ytor, hvilka ock fürefalla rütt jümna. Men rid närmare granshning risa de sig alltid uppdelaule $\mathrm{i}$ oregelmüssigt begränsade fält, hvilka sinsemellan icke äro fullt parallella utan gifva hvart och ett sin särskilda reflexbild. De till formen $z$ hörande ytorna äro små, triangulära och visserligen glänsande, men streckade parallellt med kombinationskanten till p. Den för dessa kristaller nya formen d är observerad på några fả kristaller, men ytorna äro vanligen så små, att dé, fastän glänsande, icke gifva fixerbara bilder. Blott på en kristall voro de så utvecklade, att formen genom mätning kunde tillfredsställande bestämmas. Ytorna hafva triangulär form och begränsas af ytor tillhörande pyramiderna $z$, $V$ och x. Det är en på apofyllit ytterst sällsynt form och förut, egendomligt nog, först observerad på material från Utö, enligt nppgift af Mons-Hatdnaer. ${ }^{1}$ Deras teckning visar en tjockt tafrelformig kristall af helt annan typ än den pyramidala, hvarom nu är frảga. Denna teckning återges af Scurauf i dennes Atlas ${ }^{2}$ och därifrån har den öfvergått i Daxas mineralogi. ${ }^{3}$ Vidare uppgifves formen af LévY vara funnen pã material från Fassathal. Ȧterstår af första artens pyramider formen $x$. Dess ytor utgöra ytterligt smala afstympningar af polkanterna hos formen $V$. De äro starkt glänsande och kunna förliknas vid hårfina strålar, som utgå från de

1 Treatise on Hineralogy by F. Ilons, translated by W. HAIDINaEn, 18\%5, II, p. 244, plate XVIII, fig. 98.

2 Atlas der Krystallformen, Tafel XXI, fig. 5.

s A System of Mineralogy, 1892, p. 566. Teckningen säges vara cfter Seligmasx; men denne har icke funnit formen $d$.

4 Descript. d'une Coll. de Jlin. 1837, II, p. 274. 
GEOL. FörEs. FörIIANDL. N:o 244 . Bd 28 . Häft. 6 . 4ìg

glïnsande basisytornas fyra hörn, alltsâ en fyrstrålig stjärna $p^{n ̃ ~ d e n ~ m a t t a ~ g r u n d, ~ s o m ~ b i l d a s ~ a f ~ f o r m e n ~} \nabla$. Inställes den kant $(11 \overline{5}):(11 \overline{5})$, som afstympas af $x$ parallellt med goniometeraxeln, så erhâlles ingen fixerbar bild. Inställes den düremot vinkelrät mot nämnda axel, visar sig en hârfin ljusstrimma, som både upp- och nedảt riicker ntom kikarens synfiilt. Medelst denna ljusstrimma kan formens lutning mot basis ganska skarpt bestämmas.

Af de ditetragonala pyramiderna är formen $\alpha$ tämligen vanlig hos apofyllit. Den är bestämbar genom sitt läge $\mathbf{i}$ zonerna (100:111) och (310:001). Itorna üro alltid streckade parallellt med kanten till $y$, således $i$ horisontal riktning. Formen $f$ är ny för mineralet och bestämmes därigenom, att den tillhör zonerna (310:111) och (210:001). Den uppträ̀ler $p^{a}$. dessa kristaller ungefär lika ofta som föregàende form, men dess ytor üro mindre och vanligen starkt glänsande.

Andra artens prisma, a, hör vanligen till de dominerande formerna. Dess ytor äro alltid försedda med en tämligen grof streckning i vertikal riktning. Fördjupningarna fortlöpa dock sällan till ytans grünser, utan afbrytas här och lär af tvärgảende upphöjningar. Itorna synas alltså vara fürsedda med rektangulära etsfigurer, hvars begränsning lüngsefter bildas af formen $y$ resp. $r$ och för ändarna möjligen af s. Ytpartierna mellan insänkningarna äro jämna och starkt glänsande. Ofta förlüper kring hela ytan en marginal, som är utan alla ojümnheter.

De ditetragonala prismorna $y$ och $r$ hafva vanligen ganska små ytor, men de äro i regeln jämna och utmürkt glänsande. Båda torde förekomma ungefär lika ofta. Prismat af fürsta ordningen, $m$, uppträder såsom en smal afstympning $p^{\hat{a}}$ grundpyramidens medelkanter. Itorna äro alltid försedda med tät horisontal streckning och därför nästan matta. Formen torde rara känd förut endast på material frản Korosoak, 
Grönland. ${ }^{1}$ Plover ${ }^{2}$ anger, att formen var kïnd redan af LÉvy, men dennes $m$ är icke $\{110\}$ utan $\{100\}$.

Af nu framställda förhâllanden framgår, att dessa kristaller, trots deras sirlighet och utmürkta besknffenhet i ofrigt, ingalunda äro tjänliga för noggranna rinkelbestämningar. De här nedan meddelade vinkelvärdena äro därför af ringa be. tydelse vid fastställandet af mineralets axelförhållande, utan tjüna endast som verifikation pả de sürskilda formernas be. stämning.

\begin{tabular}{|c|c|c|c|}
\hline$(111):(001)$ &.. & $\begin{aligned} & \text { Funnet. } \\
= & 60^{\prime} 18^{\prime}\end{aligned}$ & $\begin{array}{c}\text { liscräknadt. }{ }^{3} \\
60^{\prime} 21^{\prime}\end{array}$ \\
\hline$(111):(1 \overline{1} 1)$ & . . & $=75^{2} 44^{\prime}$ & $75^{\circ} 50^{\prime}$ \\
\hline$(113):(001)$ & . . & $=30^{\circ} 10^{\prime}$ & $30^{\circ} 21^{\prime}$ \\
\hline$(1.1 .10):(001)$ & . . & $=9^{\circ} 58^{\prime}$ & $9^{\circ} 58^{\prime}$ \\
\hline$(100):(001)$ & . . & $=89^{\circ} 55^{\prime}$ & $90^{\circ}-^{\prime}$ \\
\hline$(102):(001)$ & . . . & $=31^{\circ} 41^{\prime}$ & $31^{\circ} 51^{\prime}$ \\
\hline$(115):(113)$ & . . . . & $=10^{\circ} 3 \bar{r}^{\prime}$ & $10^{\prime} 59^{\prime}$ \\
\hline$(105):(001)$ & . . . & $=13^{\circ} 58^{\prime}$ & $13^{\circ} 5 \overline{7}^{\prime}$ \\
\hline$(310):(100)$ & $\cdots$ & $=18^{\circ} 00^{\circ}$ & $18^{\circ} 26^{\prime}$ \\
\hline$(210):(100)$ & . . . & $=26^{\circ} 36^{\prime}$ & $26^{\circ} 84^{\prime}$ \\
\hline$(421):(111)$ & . . . . & $=26^{3} 3^{\prime}$ & $2 \overline{7}^{\circ} 59^{\prime}$ \\
\hline$(421):(210)$ & . . . & $=9^{\circ} \overline{\bar{y}} 3^{\prime}$ & $10^{\prime} 10^{\prime}$ \\
\hline
\end{tabular}

3. Apofyllit från Skottvång.

År 1895 uppmärksammades apofyllit för första gângen i Skottvångs jürngrufvor, Srärta socken i Södermanland. Det ny'a fyndet omtalades af A. E. Nondexshrörd vid Geologiska Föreningens majsammanträde samma år. ${ }^{4}$ Mineralet förckom en tid framåt rätt ymnigt, men synes pả senare tiden åter

1 Scnrauf: Atlas der Krystallformer, Taf. XXI, fig. 4 .

2 L. c.

S Efter det pâ sìd. 9 angifna axelförhållandet.

+ G. F. F. 17: 508 . 
GEOL. FöREx. FöRHANDL. N:o 244 . Bd 28 . Häft. 6.441

hafiva upphört att visa sig. H. Bäckströs omnämner detsamma vid beskrifningen af thaumasit frản samma lokal. ${ }^{1}$

A pofylliten frản Skottvång är alltid kristalliserad. Moderstenen utgöres af en röd, stundom nästan pegmatitartad gneis, som är mer eller mindre impregnerad af magnetit, och stundom är mineralet bildadt på rena massor af denna malm. Apofyllitkristallerna ïro $i$ de flesta fall grupperade till tüta druser eller regelmässigt sammanräxta till kulformiga aggregat. Blott undantagsvis förekommer mineralet anvuxet sâsom isolerade kristallindivider.

De isoleradt förekommande kristallerna üro smâ, süllan öfver $\check{5} \mathrm{~mm}$ i utsträckning, och af något olika habitus. Än äro de prismatiska efter hnfvudaxeln, än tärningsformiga, an ater pyramidala. De prismatiska och tärningsformiga kristallerna likna dem från Utö (fig. 8, sid. 434), ehuru de üro betydligt mindre än dessa. Hnfvidformerna äro alltså:

a $\{100\}$ och c $\{100\}$,

lhrartill komma smâ afstympningar på hörnen af grundpyramiden $p$ samt en oftast obestämbar tillrundning $p^{a}$ vertikalkanterna af ditetragonala prismaformer. Kristaller af pyramidal habitus uppkomma naturligtris durigenom, att grund: pyramiden blir en af de dominerande formerna. Men här tillkommer ofta fürsta artens prisma, m, lvilken form eljest är tämligen sällsynt.

De till druser eller regelmässiga aggregat förenade kristallerna üro utprägladt tafvelformiga efter basis och ofta rätt stora. Taflor pả $3 \mathrm{~cm}$ bredd och halften så tjocka äro icke sällsynta, men de flesta äro dock betydligt mindre. Uppträdande former äro de vanliga, nämligen:

c $\{001\}$, a $\{100\}, p\{111), y\{310\}$ och (sällsynt) m $\{110\}$.

Basisytorna hos dessa kristaller äro vanligen matta, standom starkt drusiga af tätt stående spetsar, som begränsas af grundpyramidens ytelement. Andra artens prisma, a, är all-

I G. F. F. 19: 307. 
tid starkt streckadt, ofta groft trappformigt genom alternation med ytorna af formen $y$. Grundpyramidens ytor äro glïnsande, men mycket ojämna och gifva därfür mângdubl,la reflexer, hradan noggranna vinkelbestämningar här icke äro möjliga.

Såsom redan är nämndt, äro apofyllitkristallema frân denna förekomst ofta pả ett regelmässigt sïtt grupperade. De lilda nümligen kulformiga aggregat af en anmärkningsvärd regelbundenhet. De enshilda individerna äro sâ orienterade, att de alltid vända ett hörn, bildadt af $p$ och $y$, utảt. I detta hörn ändas en tvåvärdig mellanaxel, hvars andra ända befinner sig i kulans centrum. Dylika sferoliter pã a cm

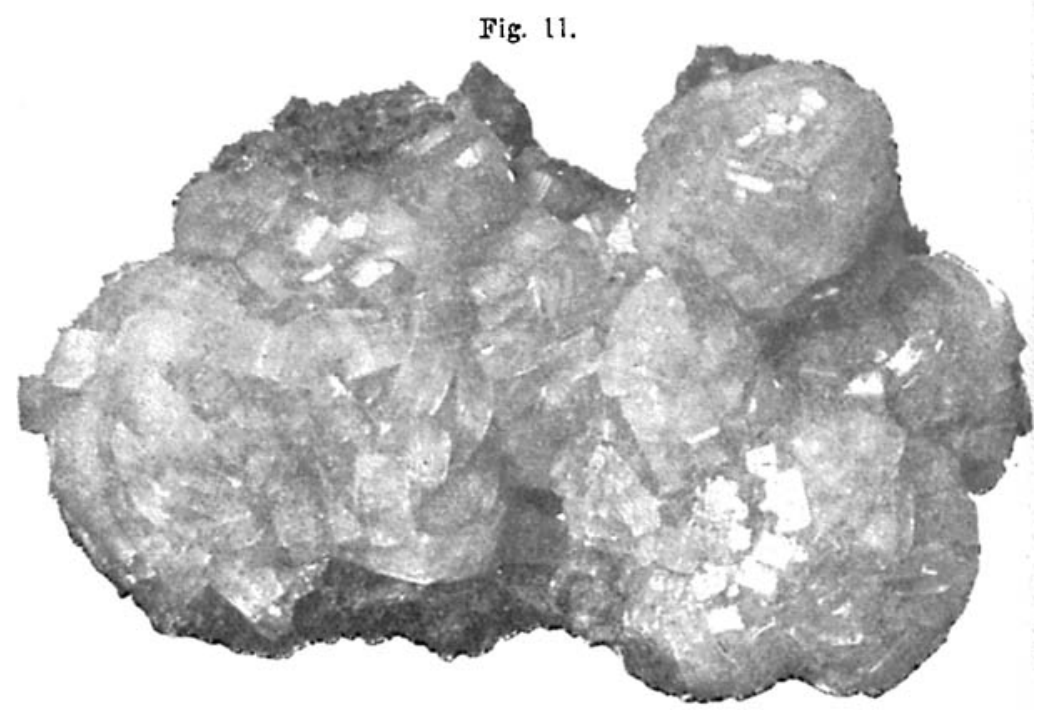

genomsnitt äro icke ovanliga (fig. 11). För det mesta äro dessa aggregat blott halfklot eller ännu lïgre svulstformiga bildningar, men stundom äro de nästan rundtom utbildade, sả att den yta, hvarmed de fastsitta, är jänförelsevis liten.

Stundom ar mineralet rattenklart, men oftast genomsättes det af en müngd fina sprickor, mot hvilka ljuset reflekteras, hvarigenom en riss mjölkalitig grumlighet uppstâr. 
GEOL. FönEs. FöRHANDL. N:o 2.4. Bd 28. IJäft. $6.443 ̈$

Apofylliten âtföljes af en del andra mineral, nämligen: mngnetit, dels som små, ofullstiindigt utbildade oktaedrar och dels som mindre körtlar med olitaedrisk afsöndring; fältspat i smâ rödn otydliga kristaller eller korn, kvarts som små mjölkhvita kristaller samt grảgrön finfjullig klorit. Sâsom saillsynthet har afven iakttagits små, väl utbildade kristaller af kalkspat och taflor af baryt. Smi svarta, limonitliknande kulor och krustor förekomma äfen gansha vanligt, men nảgon regelbunden anhopning af densamma har här icke kunnat påvisas.

\section{Apofyllit från Långbanshyttan.}

I jürn- och mangangrufvorna vid Länganshyttan air ajofyllit ett icke sällan förekommande mineral, fastän det hittills icke i litteraturen blifvit omnämndt från denna lokal. Vintern 1901-1905 anträffades och utbröts rütt mycket däraf. Men som i nämnda grufvor drushål äro mychet sällsynta, sả hur icke heller apofylliten här kunnat ntbilda sig till idiomorfa kristaller. Mineralet förekommer därför nästan uteslutande som täta massor, hvilka vid sönderslagning visa sina bladbildande genomgảngar. Fürgen ür ofta köttröd, hvilket liär gifvit anledning till förväxling med ett annat mineral. Då incsit nümligen här fồr en del år sedan först uppmärksammades, antogs den, just på grund af sin röda fürg och sin strâliga textur, vara apofyllit.

Fritt utbildade apofyllitkristaller äro alltså vid denna fürekomst ytterst sällsynta, och såvidt kïndt är, finnas blott ett jar stycken med dylika, hrilka tillhöra -den Sjögrensha samlingen vid Riksmuseum. Pá dem finnas blott några fả kristaller, hvilka dessutom endast delvis äro fritt utbildade. Det är nämligen endast nảgra ur de oregelbundna, bladiga massorna framskjutande lanter och hörn, som visa regelmässig kristallbegränsning. 
Moderstenen utgör en mörkt grảbrun, derb granatmassa, som här och dür visar en svag antydan till kristallbegrüns. ning af ikositetriedern \{211\}. Mellan denna granat och apofyllitkristallerna finnes ranligen ett tunt lager af magnetit.

De utbildade kristallpartien tyda pã indirider af ett par centimeters storlek. Till sin habitus kunna kristallerna săgas vara tjockt tafvelformiga (fig. 12), men stundom üro indiri. derna ungefür lika tjocka som breda. De begrä̈nsas af föl. jande former:

$$
\text { c }\{001\} \text {, a }\{100\}, \mathrm{p}\{111\}, \mathrm{i}\{101\}, \mathrm{b}\{102\} \text { och } \mathrm{V}\{105\} \text {. }
$$

Dessa liristallers tafvelformiga habitus betingas af den dominerande stallning, basis och formen $V$ intaga i ytkombinationen. Genom dessa bâda formers inbördes relation erhâlla kristallerna också en riss analogi med dem af pyramidala

Fig. 12.

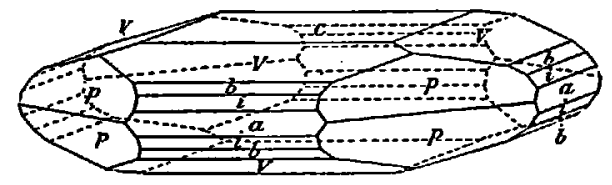

typen från Utö. Men den skarpa och sirliga begrïnsning de båda furmerna emellan, hvilken utmürker Utökristallerna, fiunes icke på dem frân Lảugbanshyttan. Hủr öfvergå de genom tillrundning och alternationsstreckning $i$ hvarandra, hradan såväl basis som ytorna of formen $V$ üro starkt strecknde parallellt med deras gemensanma kombinationskanter. Formerna $i$ och b äro båda utomordentligt sällsynta. Den förra iakttogs, såsom redan är nämndt, af Seligmaxis (l. c.) på en kristall från Utö. Den senare är observerad af Ploner (l. c.) på material från Seiseralp. På kristallerna från Lảngbanshyttan äro de tämligen vanliga, men ytorna äro mycket smala, isynnerhet de af formen i. Grundpyramidens ytor äro starkt glänsande och på de mindre individerna också tämligen jümna. $\mathrm{Pà} \mathrm{de} \mathrm{större} \mathrm{ater} \mathrm{förekommer} \mathrm{regelbundet} \mathrm{en} \mathrm{vågformig} \mathrm{alter-}$ 
GEOL. FöREx. FöRHANDI. N:0 944. Bd 28. Häft. 6.445 nation med en visinalform i zonen [111:001], hrilken form med hufrudytan bildar en rinkel på c:a $21 / 2^{\circ}$. Pả formen a forrckommer en fin rutighet parallellt med kanterna till p; men i öfrigt äro denna forms ytor jämna och glänsande.

Af det nu anförda torde frangả, att dessa kristaller icke egna sig för noggranna vinkelbestämningar. Följande värden af'se därför endast de anförda formernas identifiering.

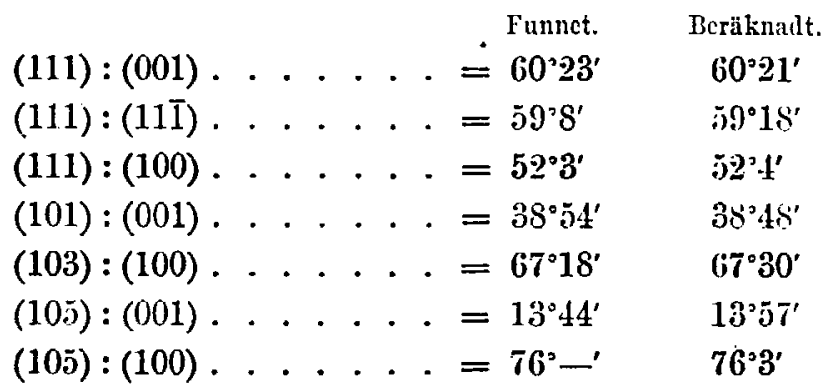

Den förnt omnämnda röda färgen hos mineralet gäller hufvudsakligen de derba mossorna. De utbilade kristallerna läremot äro helt färglösa och vattenklara eller visa en knappt märkbar dragning åt rosenrödt.

\section{万. Apofyllit från Hällestad.}

Sâsom redan inledningsvis omnämndes, upptäcktes mineralet apofyllit år 1783 vid den då odelagda Sörgrufvan $i$ Hällstad, Ostergötland, af d. v. auskultanten i Bergskollegium Carr Rinuas. Anledningen till hans undersökning af mineralet anger han sjulf bland annat hafva varit att utröna, huruvida det skulle kunna användas rid tillrerkning af glas, med livilket det hade en stor likhet. Samtidigt med Rinuan undersökte också l'onbern Berasan detsamma, och de båda forskarna kommo vid sina arbeten till nästan samma resultat. ${ }^{1}$

1 Vet. Akad. Handl. 5, 1784, s. 116. Bergandx yttrar sig med anledning af sin och Rrsuss undersökning pa füljande sätt: Jag fann med nöje en nästan fullständi: of verensstämmelse mel mina cgma, hvilkct bevisar, att 
Något vidare bidrag till kännedomen om apofylliten fràn Hällestad erhölls icke förr än âr 1878, dâ $P$. Grorn $i$ sin beskrifning öfver mineraliesamlingen i Strassburg ${ }^{1}$ omnämner denna fyndort och säger, att de liumbladiga aggregaten ut. löpa i tjocka taflor, som likna dem frản Seiseralp.

Riksmuseets förrâd af apofyllit frản Hällestad bestâr af blott 4 stycken. Dessa utgöras af nüstan uteslutande apofyllit och kalkspat, sã att man af dem icke fảr något begrẹp om moderstenens beskaffenhet. Små partier af magnetit och ett lager af askgrå, jordartad förrittringsprodukt ür det enda medföljande. Kalkspaten tyckes hafva bildat stora hexagonala prismor, ur hvilka framskjuta romboedrar med sâ lâg hufvudaxel, att de se ut nüstan som tunna basiska taflor. Tvifrelsutan är denna kalkspat yngre än apofylliten.

Redan Rivsan uppmärksammade kristaller af mineralet, och han har för sin afhandling üfven framställt en afbildning af en kristalldrus. Med den tidens kristallografiska insikter och hjülpmedel kunde resultatet af hans försök i denna räg icke blifva mycket upplysande. Han säger, att kristallerna likna stuppkamskristaller af tungspat.

Det nu tillgängliga materialet består till största delen af bladiga massor utan regelmässig kristallbegränsning. Luamellerna, som stundom radiellt ntlöpa från ett centrum, aro ofta skål- eller cylinderformigt böjda. I det inre har mineralet fläckvis köttröd färg; dürimellan är det silfverhvitt, och utlöpande kristaller äro fürglösa och klara.

Kristaller förekomma mycket sparsamt pã två af styckena. De äro tafvelformiga efter basis, och de största uppnả $2 \mathrm{~cm}$ i bredd samt $4 \mathrm{~mm}$ i tjocklek. Kombinationen är enkel och bestâr af blott följande former (fig. 3, sid. 428):

$$
\text { c }\{001\} \text {, a }\{100\} \text { och } p\{111\} \text {. }
$$

dả vederbörlig noggrannhet användes, linnna annlytiska försök af flera personer på vidt aflïgsna orter anstillas, utan nagon betydlig sbillnail i atslagen.3

${ }^{1}$ Jie Jineraliensamlung der Kais. Will. Universität, Strassburg, s. $20 \overline{5}$. 


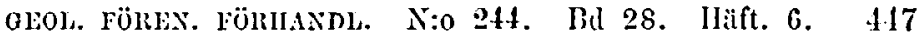

Likasom de oregelmässiga, bladiga massorna äro äfren kristalltaflorna ofta böjda, men i öfrigt äro ytorna rätt jümna och glänsande. Blott basisytorna äro något matta, men äga dock en vacker pärlemorglans. De äro försedda med en mycket fin, koncentriskt kroklinig striering, som eljest sällan visar sig pâ kristallytor. Äfren äro dessa ytor beströdda med ytterligt små, glänsande svafvelkiskristaller. Pâ de till formen a hörande ytorna förekomma ofta mycket låga, pyramidala upphöjningar af rombisk form och orienterade parallellt med begränsningen mot p. Pả större ytor stả flera dylika upphöjningar tätt bredvid hvarandra, men på mindre dylika finnes vanligen blott en sådan, hvilken upptager nästan hela ytan. En dylik yta ger pá geniometern \pm fullt regelbundet orienterade reflexer, af hvilka de motstående ligga på $40^{\prime}$ afstảnd frin hvarandra. Äfven grundpyramidens ytor äro hos dessa kristaller anmärkningsvärdt jümna och alltid starkt glänsande.

Fig. 13.

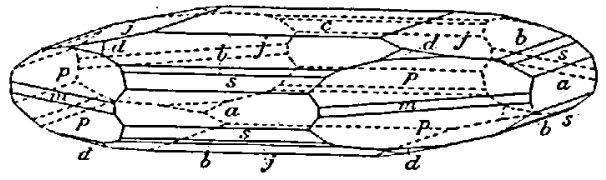

Utom dessa större och till sin kombination enkla kristaller förekomma üfven, ehuru mycket sparsamt, ganska smâ, men ytrikare kristalltaflor, af hvilka figur 13 ger en afbildning. De här uppträdande formerna äro följande: $c\{001\}, \quad a\{100\}, \quad p\{111\}, \quad z\{113\},{ }^{1}$ d $\{115\}, \quad m\{110\}, \quad b\{102\}$, $\mathrm{s}\{103\}$ och $\mathrm{j}\{109\}$.

Detta ïr en ganska märklig kombination. I viss mån äro dessa kristaller analoga med dem frản Långloanshyttan och med de pyramidala frản Utö. Men medan på de senare den flacka pyramiden $V$ med stora mattstreckade ytor omgifver

1 Formen $z$ är icke tecknad på figuren. Dess läge är naturligtris mellan p och d. 
basis, så spelar â liristallerna frản Hällestad den ännu flac. kare $\mathrm{j}$ samma rol. Denna form är förut iakttagen blott af PlONER ${ }^{1}$ pâ hans af vicinalformer öfversallade material frản Seiseralp och kunde dürför knappt betraktas som fullt säkert konstaterad, själfständig form. På kristallerna från Hällestarl uppträder den regelbundet på alla fullt utbildade individer. Ytorna äro jümförelsevis stora, men alltid streckade parallellt med hanterna mot hasis. Andra sällsynta former äro här d, $m$ och b. Den fürstuiimnda diskuterades vid redogörelsen für de pyramidala kristallerna frân Utö, och den sistnämnda viil beskrifningen af dem frîn Långbanshyttan. Första artens prisma, m, är förut känd blott på kristaller från Utö och frản Korosoak, Grönland (jümf. sid. 439). Blott pả en kristall från Hällestad är denna form observerad, men ytan är stor och văl utbildad.

Alla former på dessa liristaller, med undantag af lasis och pyramiden $j$, äro väl utbildacle med jämna och glänsande ytor, så att de med noggrannhet kunnat bestämmas. Basis. ytorna äro vanligen försedda med ett slags streckning af vågformigt böjda små gropar och åsar, en företeelse som icke kan vara identisk med ranlig kombinationsstreckning. De gifra därför $\mathbf{i}$ allmänhet mycket dimmiga och obestämda reflexbilder.

De särskilda formernas bestämmande grundar sig på följande vinkelvärden:

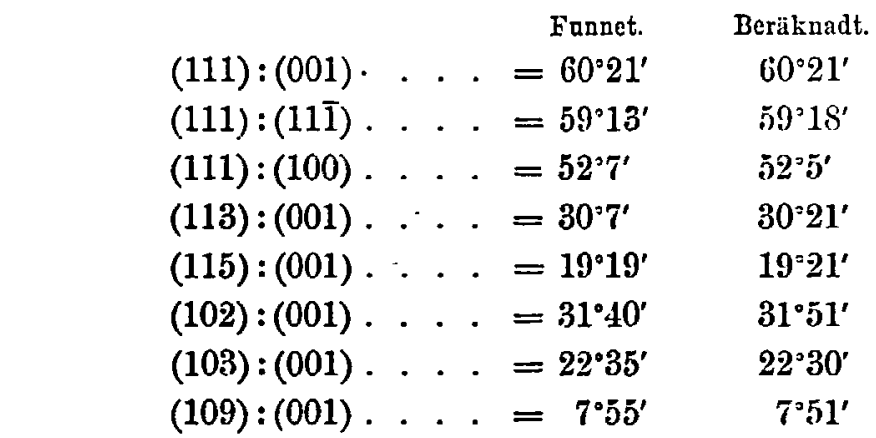


GEOL. Fören. FörhandL. N:o 244. Bd 28. Häft. 6. 449

De beräknade värdena grunda sig här likson fürut pâ det â kristallerna från Taberg (och från Island) funna axelförhâllandet: a: $c=1: 1.24215$. Nüstan üfverallt, där noggranna bestämningar varit möjliga, är öfrerensstämmelsen mellan funna och beräknade värden så god, att nämnda axelförhâllande kan anses uppfylla berättigade kraf pã noggrannhet, åtminstone för mineralet från de nu undersökta fyndorterna. Visserligen gâfro de tafrelformiga kristallerna från Nordmarken ett något olika resultat, men afren detta afrịker från det för mineralet allmängiltigt antagna axelförhållandet, och afvikelsen går i samma riktning som det nu föreslagna.

Såsom allmänt resultat af denna undersökning torde alltsâ följande satser kunna uppställas:

1. Apofylliten visar ofta $i$ sin livistallbyggnad sådana oregctmässigheter, att noggranna vinliclbestämningav iclic äro möjliga, och detta torde cara orsalien till de mainga olika resultat, hvartill olika forslare lommit vial sina försök att fastställa detta minerals liristallografiska konstanter.

2. Vid omsorgsfullt val af material liunna dock: vimnas med hearandra ganska nära öfverensstämmande vesultat, hrillia rätt väsentligt afvilia frian de för mineralet hittills gällandt.

3. Axelförhållandet

$$
a: c=1: 1.24215
$$

torde $i$ de flesta fall motsuara de förhandenvarande vinkeldimen. sionerna.

4. Smärre afvikelser $i$ dessa dimensioner föreliomma dock, leilka synas rava bundna vid särskilda lokala utbildningsförhaillanden.

Slutligen meddelas en tabell, som visar de särskilda formernas förekomst på apofyllit från de här behandlade svenska fyndorterna. 


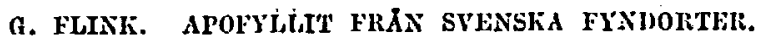

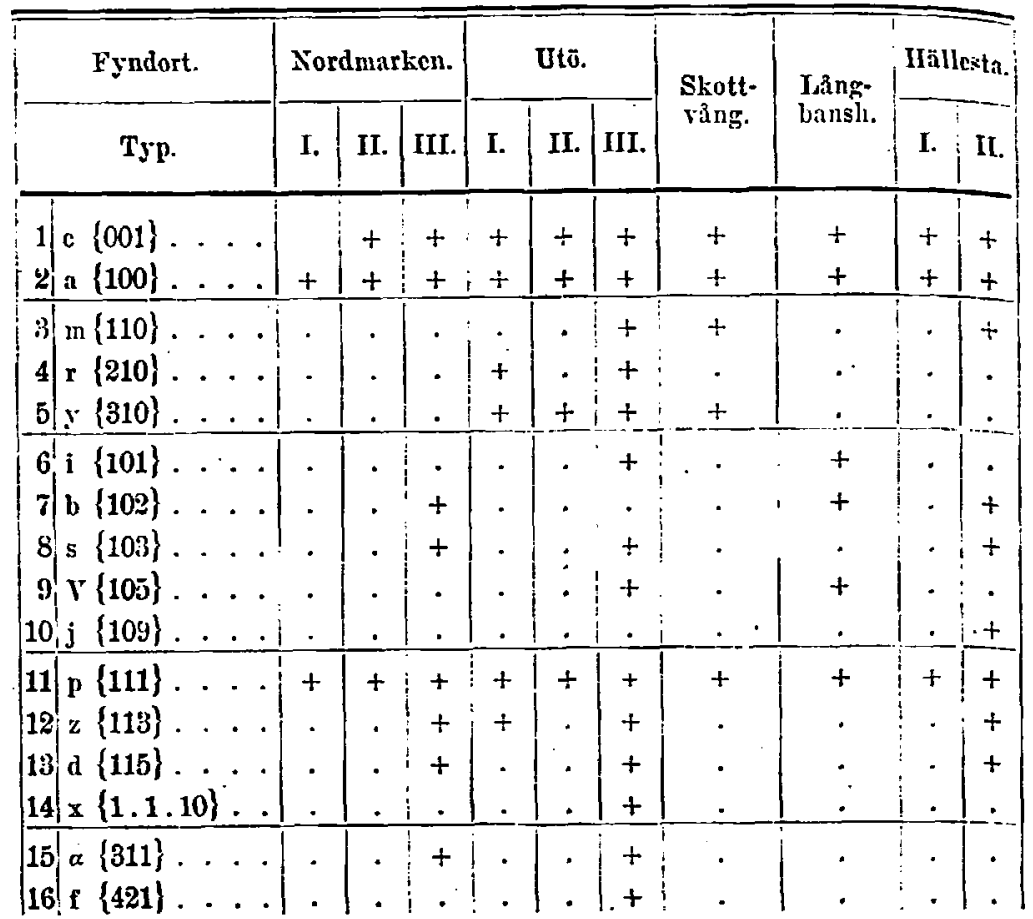

